\title{
Standard Cubic Meter
}

National Cancer Institute

\section{Source}

National Cancer Institute. Standard Cubic Meter. NCI Thesaurus. Code C68858.

A unit used in physical chemistry to express the amount of substance of an ideal gas in one cubic meter at standard (according to DIN 1343 standard) conditions: temperature $273.15 \mathrm{~K}$ and pressure of one atmosphere (101.325 kPa). 